Obere Extremität 2019 $\cdot 14: 127-135$ https://doi.org/10.1007/s11678-019-0507-3 Received: 12 October 2018 Accepted: 23 January 2019 Published online: 15 February 2019 (c) The Author(s) 2019

\author{
Alexandre Lädermann $n^{1,2,3}$ D J Joe Chih-Hao Chiu ${ }^{4}$ Philippe Collin ${ }^{5}$. \\ Sébastien Piotton' ${ }^{1}$ Luca Nover ${ }^{6}$ - Markus Scheibel ${ }^{7,8}$ \\ ' Division of Orthopedics and Trauma Surgery, La Tour Hospital, Meyrin, Switzerland \\ ${ }^{2}$ Faculty of Medicine, University of Geneva, Geneva, Switzerland \\ ${ }^{3}$ Orthopedics and Trauma Service, University Hospitals of Geneva, Geneva, Switzerland \\ ${ }^{4}$ Department of Orthopaedic Sports Medicine, Chang Gung Memorial Hospital, Taoyuan City, Taiwan \\ ${ }^{5}$ Centre Hospitalier Privé Saint-Grégoire (Vivalto Santé), Saint-Grégoire, France \\ ${ }^{6}$ ReSurg SA, Nyon, Switzerland \\ ${ }^{7}$ Schulthess Clinic, Zurich, Switzerland \\ ${ }^{8}$ Center for Musculoskeletal Surgery, Charité-Universitaetsmedizin Berlin, Campus Virchow, Berlin, \\ Germany
}

\section{Hemi- vs. reverse shoulder arthroplasty for acute proximal humeral fractures}

\section{A systematic review of level I and II studies}

\section{Introduction}

Proximal humeral fractures (PHF) represent between 4 and $10 \%$ of all bone fractures and occur more frequently in elderly patients $[18,24,39]$. Their incidence is expected to increase considerably over the coming years owing to aging of the population $[16,34]$. Acute threeand four-part PHF can be challenging to treat, particularly if they involve the humeral head or tuberosities $[9,11,21$, 23].

Decision-making in the treatment of PHF is influenced by different factors, including patient age and functional status, bone quality, fracture pattern, tuberosity involvement, as well as surgeon preferences [1, 34]. Traditionally, when fixation is not possible because of poor bone quality and risks of nonunion or osteonecrosis, acute PHF can be managed by shoulder hemiarthroplasty (HSA; - Fig. 1; [11, 34, 39]). Although HSA has fewer complications and grants better function than internal fixation systems, it remains associated with inconsistent outcomes, particularly in elderly patients, owing to proximal humeral migration as well as osteolysis, malunion, nonunion, or tuberosity resorption [15, 33, 34, 39].
In recent years, reverse shoulder arthroplasty (RSA; - Fig. 2) gained acceptance as an alternative treatment for complex PHF in elderly patients [11, $15,39]$, because it relies on the deltoid muscle to restore shoulder function and hence circumvents poor tuberosity healing or concomitant rotator cuff tears [24, 34]. Despite encouraging results, many surgeons hesitate to treat acute PHF by RSA, because it is more invasive and could lead to potentially more complications in the long term $[4,7,11,15,33$, 34, 39].

To date there is no clear consensus on the superiority of HSA or RSA for the treatment of acute PHF. We therefore aimed to review the relevant literature for studies of high levels of evidence, reporting clinical outcomes and revision rates for HSA or RSA for the treatment of acute PHF.

\section{Table 1 Keyword search terms}

\begin{tabular}{|c|c|c|c|}
\hline \multicolumn{2}{|c|}{ Database search } & \multirow{2}{*}{$\begin{array}{l}\text { Medline } \\
5155\end{array}$} & \multirow{2}{*}{$\begin{array}{l}\text { Embase } \\
6675\end{array}$} \\
\hline 1 & shoulder AND arthroplasty & & \\
\hline 2 & hemi* OR reverse* & 552,834 & 979,464 \\
\hline 3 & proximal* AND fracture* AND humer* & 3489 & 4573 \\
\hline 4 & score* OR revision* OR outcome* & $2,686,081$ & $3,761,045$ \\
\hline 5 & \#1 AND \#2 AND \#3 AND \#4 & 328 & 413 \\
\hline
\end{tabular}

\section{Material and methods}

An electronic literature search was conducted using the Medline (PubMed) and Embase libraries on 22 September 2018 for articles on HSA and RSA using the following keywords: (shoulder AND arthroplasty) AND (hemi* OR reverse ${ }^{\star}$ ) AND (proximal ${ }^{\star}$ AND fracture ${ }^{\star}$ AND humer $^{\star}$ ) AND (score ${ }^{\star}$ OR revision ${ }^{\star}$ OR outcome*; - Table 1). The electronic literature search returned 741 records that were screened to determine relevance in accordance with the established guidelines of the Preferred Reporting Items for Systematic Reviews and Metaanalysis (PRISMA; [26]):

\section{Search strategy}



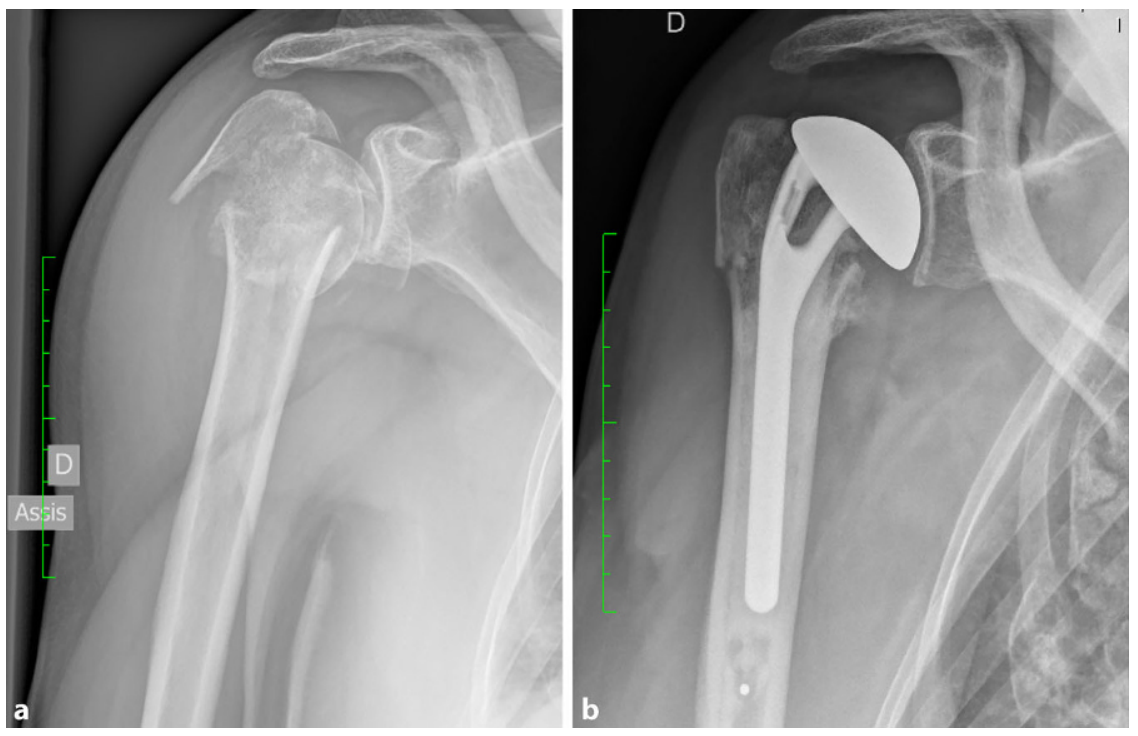

Fig. 1 S Shoulder hemiarthroplasty radiographs: a preoperative; b at 6-week follow-up
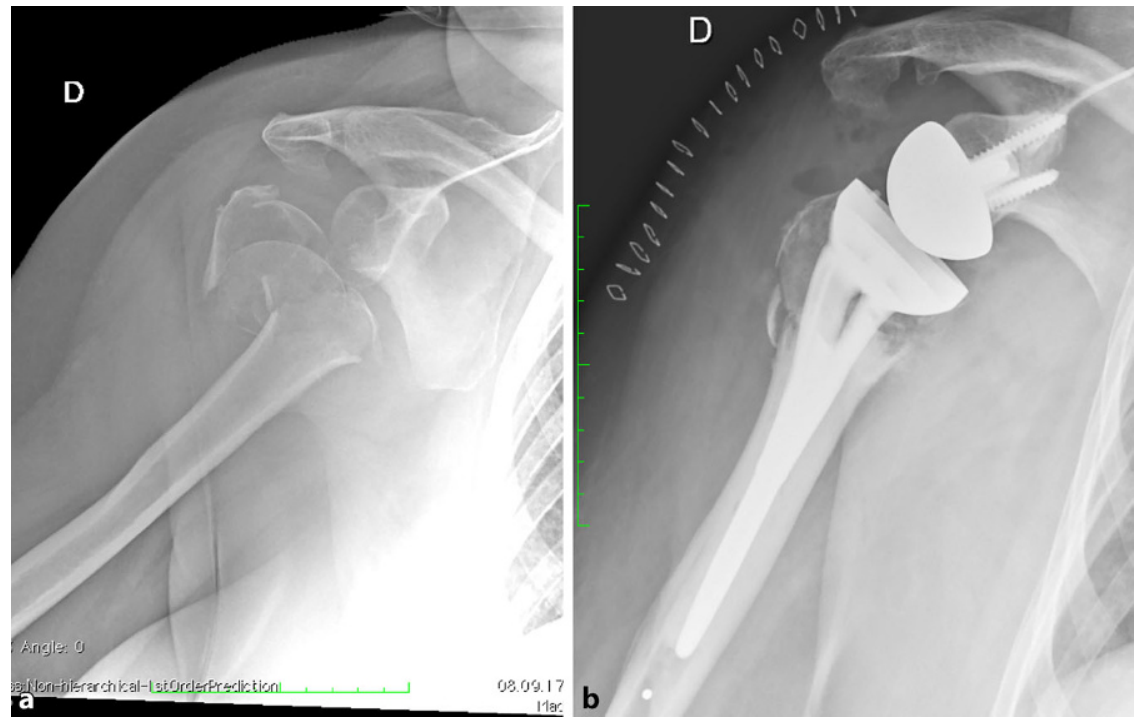

Fig. $2 \Delta$ Reverse shoulder arthroplasty radiographs: a preoperative; b at 6-week follow-up

\section{Inclusion criteria}

- Level I or II studies reporting clinical and/or radiographic outcomes of primary HSA or primary RSA as treatments for acute PHF

\section{Exclusion criteria}

- Level III, IV, or V studies

- Studies reporting outcomes of revision HSA or revision RSA

- Studies reporting outcomes for treatments of non-acute PHF, such as sequelae fractures or PHF with diaphyseal extension
- Articles written in languages other than English, French, German, Italian, or Spanish

- Articles published before 1998

A total of 148 articles were duplicates, 569 were excluded by reading their titles and/or abstracts, and a further 15 articles were excluded by reading their full text, because they were not level of evidence I or II studies. No additional relevant articles were identified from citations in the full-text articles. This left a total of nine articles from which data were extracted for this review (• Fig. 3; [2, 3, 6, 8, 11, $22,28,32,37])$.
Data extraction and quality assessment

Two investigators (LN and AM) independently tabulated and verified the following data from each article: first author, study design, etiology, treatment, cohort size, age at surgery, follow-up, clinical and radiographic outcomes, reported complication, and revision rate. In cases of discrepancies between abstract and full text, data were extracted from the most comprehensive source. Disagreements were discussed until consensus was reached.

Level I studies were evaluated for bias using the Jadad Scale [20] as modified by Gummesson et al. [19], which evaluates randomization method, blinding, and description of dropouts/withdrawals with preset scores for each question from -1 to 1 point. Total scores range from -2 (lowest quality) to 5 (highest). Level II studies were evaluated for quality using the Methodological Index for Non-randomized Studies (MINORS) checklist [35], which assesses articles on 12 methodological items. Scoring is as follows: 0 , not reported; 1 , reported but poorly done and/or inadequate; and 2 , reported in a well-done and adequate manner. Total scores range from 0 (lowest quality) to 24 (highest quality). Each study was scored by two independent investigators (LN and AM). Disagreements were discussed until consensus was reached.

\section{Results}

The nine selected articles were published between 2011 and 2016, four of which were level I studies according to their level of evidence statements $[2,6,28,32$, 37], three of which were level II studies according to their level of evidence statements $[3,8,11,22]$, and the remaining two were deemed to be level II studies, although they did not explicitly state the level of evidence ([2, 6, 28, 32, 37]; - Table 2). Only three studies [3, $11,32]$ directly compared outcomes of acute PHF treated by HSA versus RSA. The remaining six studies compared outcomes of acute PHF treated by conventional HSA versus HSA + biceps tenodesis [37], trabecular metal HSA [22], in- 
Obere Extremität 2019 · 14:127-135 https://doi.org/10.1007/s11678-019-0507-3

(c) The Author(s) 2019

A. Lädermann · J. C.-H. Chiu · P. Collin · S. Piotton · L. Nover · M. Scheibel

\section{Hemi- vs. reverse shoulder arthroplasty for acute proximal humeral fractures. A systematic review of} level I and II studies

Abstract

Background. To date, there is no clear consensus on the superiority of shoulder hemiarthroplasty (HSA) or reverse shoulder arthroplasty (RSA) for the treatment of acute proximal humeral fractures (PHF).

Objectives. The aim of this study was to review the relevant literature for level I and Il studies reporting clinical outcomes and revision rates for HSA or RSA in the treatment of acute PHF.

Methods. Two electronic databases (PubMed, and Embase) were systematically searched for level I and II studies published after 1998 reporting clinical and/or radiographic outcomes of primary HSA or primary RSA as treatments for acute PHF.
Results. Of the 628 studies that were identified, nine were selected (four level I and five level II), with some heterogeneity in describing outcomes, complications, and revisions. The three studies that compared HSA versus RSA in patients with a mean age of $>70$ years found that RSA grants better clinical scores, less pain, higher forward elevation, and greater patient satisfaction. The remaining six studies compared outcomes of acute PHF treated by conventional HSA versus $\mathrm{HSA}$ + biceps tenodesis, trabecular metal HSA, intramedullary fibular allograft with locking compression plates, open reduction with internal fixation, or nonoperative treatment.
Conclusion. Reverse shoulder arthroplasty is a reliable treatment for acute PHF in elderly patients, which grants better outcomes and is associated with fewer complications than HSA at short-term follow-up. Future research is needed to establish the best surgical treatment for acute PHF in young patients. Level of evidence. Level II, systematic review of level I and II studies.

\section{Keywords}

Hemiarthroplasty - Shoulder replacement . Prosthesis - Fracture humerus - Elderly . Treatment outcome

\section{Hemi- vs. inverse Schulterarthroplastik bei akuten Frakturen des proximalen Humerus. Systematische Übersichtsarbeit zu Level-I- und Level-II-Studien}

\section{Zusammenfassung}

Hintergrund. Bisher herrscht kein eindeutiger Konsens zur Überlegenheit der HemiSchulterarthroplastik (HSA) oder der inversen Schulterarthroplastik (RSA) zur Behandlung von akuten Frakturen des proximalen Humerus (PHF).

Ziel der Arbeit. Ziel der Studie war ein Überblick über die relevante Literatur in Bezug auf Level-I- und Level-II-Studien zu klinischen Ergebnissen und Revisionsraten nach HSA oder RSA als Therapie einer akuten PHF. Methoden. Systematisch wurden 2 elektronische Datenbanken (PubMed und Embase) nach Level-I- und Level-II-Studien durchsucht, die nach 1998 veröffentlicht wurden und Angaben zu klinischen und/oder radiologischen Ergebnissen der primären HSA oder primären RSA als Therapie der akuten PHF enthielten.
Ergebnisse. Von den 628 entsprechenden Studien wurden 9 ausgewählt (4 Level I und 5 Level II), dabei bestand eine gewisse Heterogenität in der Angabe der Ergebnisse, Komplikationen und Revisionen. In den 3 Studien mit einem Vergleich zwischen HSA und RSA bei Patienten im Durchschnittsalter von $>70$ Jahren stellte sich heraus, dass die RSA zu besseren klinischen Werten, geringeren Schmerzen, höherer Elevation nach vorn und größerer Patientenzufriedenheit führte. Bei den übrigen 6 Studien wurden die Ergebnisse der Behandlung einer akuten PHF mit konventioneller HSA verglichen mit HSA + Bizepstenodese, HSAProthese aus trabekulär aufgebautem Metall, intramedullärem Fibulaallograft mit winkelstabilen Kompressionsplatten, offener Reposition mit interner Fixation oder nichtoperativer Behandlung.

Schlussfolgerung. Die RSA stellt eine reliable Therapie bei akuter PHF älterer Patienten dar, die zu besseren Ergebnissen führt und mit weniger Komplikationen als die HSA im kurzfristigen Follow-up einhergeht. Zukünftige Untersuchungen sind erforderlich um festzustellen, welches die beste chirurgische Therapie einer akuten PHF bei jungen Patienten ist.

Evidenzlevel. Level II, systematische Übersichtsarbeit zu Level-I- und Level-IIStudien.

\section{Schlüsselwörter}

Hemiarthroplastik · Schulterersatz $\cdot$ Prothese . Humerusfraktur · Senioren - Therapieergebnis tramedullary fibular allograft with locking compression plates [8], open reduction with internal fixation (ORIF; [6]), and nonoperative treatment $[2,28]$. It is worth noting that two studies $[22,32]$ performed biceps tenodesis as a routine procedure on all patients. On a scale of -2 (poorest) to 5 (highest) for quality assessment [19], of the four level I studies, three scored 3 points $[2,28,32]$ and one scored 5 points [37]. On a scale of 0 to 24 , of the four prospective level II studies, one scored 15 points [3], one 17 points [8], one 21 points [6], and two 23 points $[11,22]$.

The cohort sizes ranged from 12 to 69 patients per group while the mean follow-up ranged from 1 to 4.6 years. The mean patient age was $>70$ years in six studies [2, 3, 6, 11, 28, 32], between 60 and 70 years in two studies [8, 22], and between 50 and 55 years in one study [37].
In all studies, the fracture etiology was classified according to the Neer classification [27] as acute three-part, four-part, or head-splitting PHF. The most frequently reported clinical outcomes were the absolute or adjusted Constant scores (• Fig. 4), the Disability of the Arm, Shoulder and Hand (DASH) Score [17], the University of California-Los Angeles (UCLA) Score [14], and the American Shoulder and Elbow Surgeon (ASES) Score [25]. 


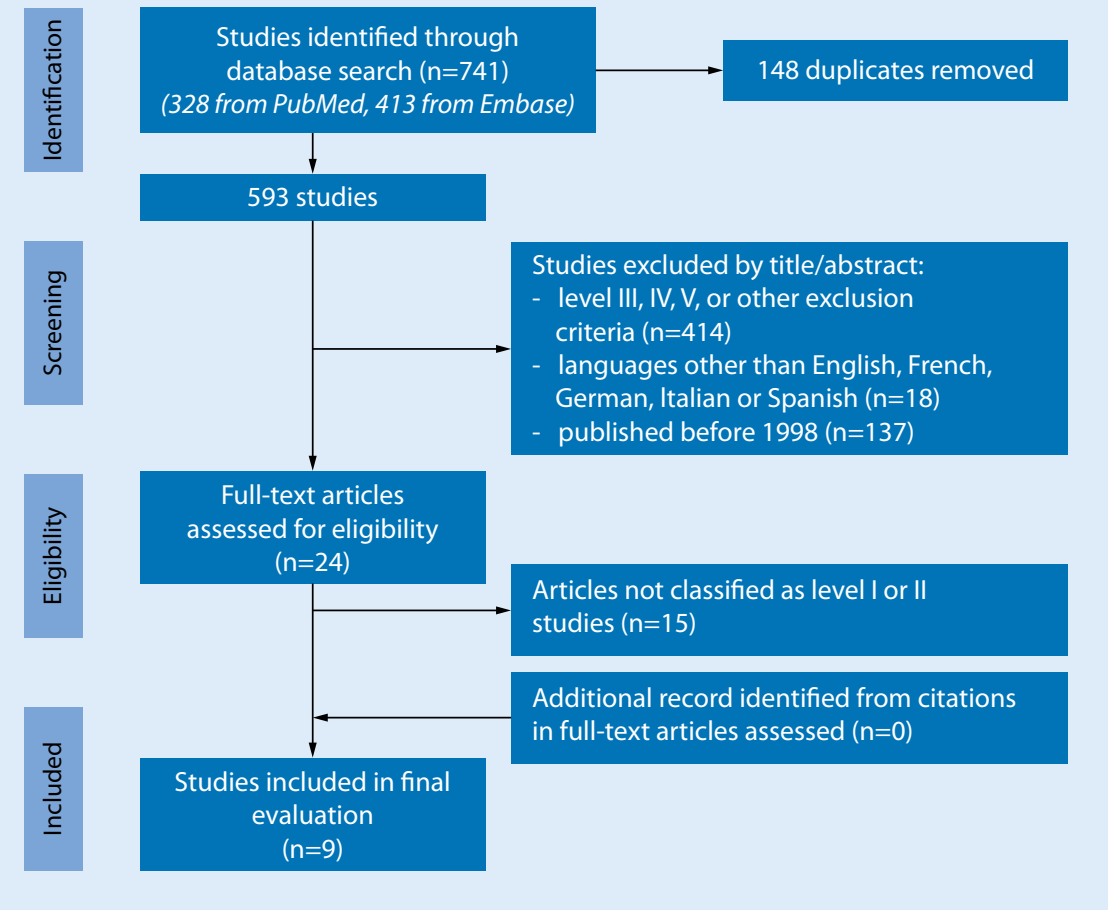

Fig. $3 \triangle$ PRISMA flow diagram

Forward flexion $[2,3,8,11,22,32,37]$ and external rotation $[2,3,6,8,11,22$, 32 ] were each reported in seven articles, while internal rotation was reported in four articles [2, 8, 22, 32], and abduction was reported in four articles [2, 3, 8, 32]. Five studies [2, 11, 22, 28, 32] reported tuberosity malunion or resorption. Finally, all studies reported complications and revisions (• Fig. 5), while only one study [32] reported on the Kaplan-Meier survival (• Table 3 ).

There was some heterogeneity across studies in reporting outcomes, complications, and revisions. Li et al. [22] only reported radiographic complications related to the greater tuberosity and Soliman et al. [37] merely reported pain complications. Clinical outcomes were different (e.g., Constant score vs. ASES scores) as well as measurement references (external rotation alone vs. external rotation as part of the Constant score). Two studies also presented subgroup analyses of their cohorts based on radiographic findings of the greater tuberosity [11,22]. Boyer and coworkers' level II study presented considerable heterogeneity across HSA and RSA cohorts in mean follow- up (2.1 vs. 1.3 years) and in mean patient age (68 vs. 78 years; [3]).

\section{HSA vs. RSA}

Only three studies [11, 32] directly compared HSA with RSA, one of which [28] compared locked-stem HSA with lockedstem RSA. All three studies reported outcomes in patients with a mean age of $>70$ years and found that RSA grants better clinical scores, less pain, higher forward elevation, and greater patient satisfaction. Neither Sebastiá-Forcada et al. [32] nor Cuff and Pupello [11] reported significant differences in internal rotation, while Sebastiá-Forcada et al. [32] reported a significantly better external rotation in the RSA group. The two studies without locked stems [11,32] also agreed that tuberosity malunion or resorption negatively influenced outcomes for the HSA groups but not for the RSA groups. Furthermore, compared with RSA, both complications and revisions were more frequent following HSA without locked stems [11, 24], with only one revision among all RSA patients. Among HSA patients, a total of 11 revisions were described due to resorption of the tuberosi- ties and resultant pseudoparesis of the shoulder [11], to an acromion-head distance of $\leq 7 \mathrm{~mm}$, reflecting insufficiency or rupture of the rotator cuff [32], or to secondary cuff rupture ([39]; - Table 3).

\section{Other findings}

Among the selected articles, a single study [22] compared outcomes of different humeral prostheses, one conventional and the other using trabecular metal, in patients treated with HSA (with adjuvant biceps tenodesis). Compared with the conventional HSA group, at a mean follow-up of 4.6 years, the trabecular metal HSA group had fewer radiographic complications related to the greater tuberosity ( $25.7 \%$ vs. $6.1 \% ; p=0.028)$, higher ASES (72 vs. $81 ; p=0.012)$ and UCLA (25 vs. $28 ; p=0.007)$ scores, greater active forward elevation $\left(131^{\circ}\right.$ vs. $116^{\circ}$; $p=0.044)$ and external rotation $\left(38^{\circ}\right.$ vs. $\left.30^{\circ} ; p=0.015\right)$, but no difference in internal rotation $(p=0.671)$ or pain on the visual analog scale $(p=0.779)$.

Only one study compared outcomes of HSA with and without adjuvant treatment [37]. Reporting clinical outcomes at 2 years for patients aged 50-55, Soliman et al. [37] found that, compared with HSA alone, HSA with biceps tenodesis granted significantly better age- and gender-adjusted Constant scores (74.4 vs. $69.8 ; p=0.04)$, reduced the occurrence of pain ( $15.8 \%$ vs. $33.3 \% ; p=0.03)$, and tended to increase the range of forward elevation $\left(152^{\circ} \pm 18^{\circ}\right.$ vs. $\left.1^{\circ} \pm 16^{\circ} ; p>0.05\right)$.

\section{Discussion}

The most important finding of the present literature review is that, from the nine relevant level I and II studies that reported clinical outcomes and revision rates of primary HSA or RSA in treating acute PHF, only three studies $[3,11,32]$ directly compared HSA with RSA. All three stated that RSA had better clinical scores and fewer revisions than HSA in elderly patients. Given that only one study described outcomes for patients aged $<60$ [37], the best surgical treatment in young and more demanding patients remains under debate $[5,10,30]$. 


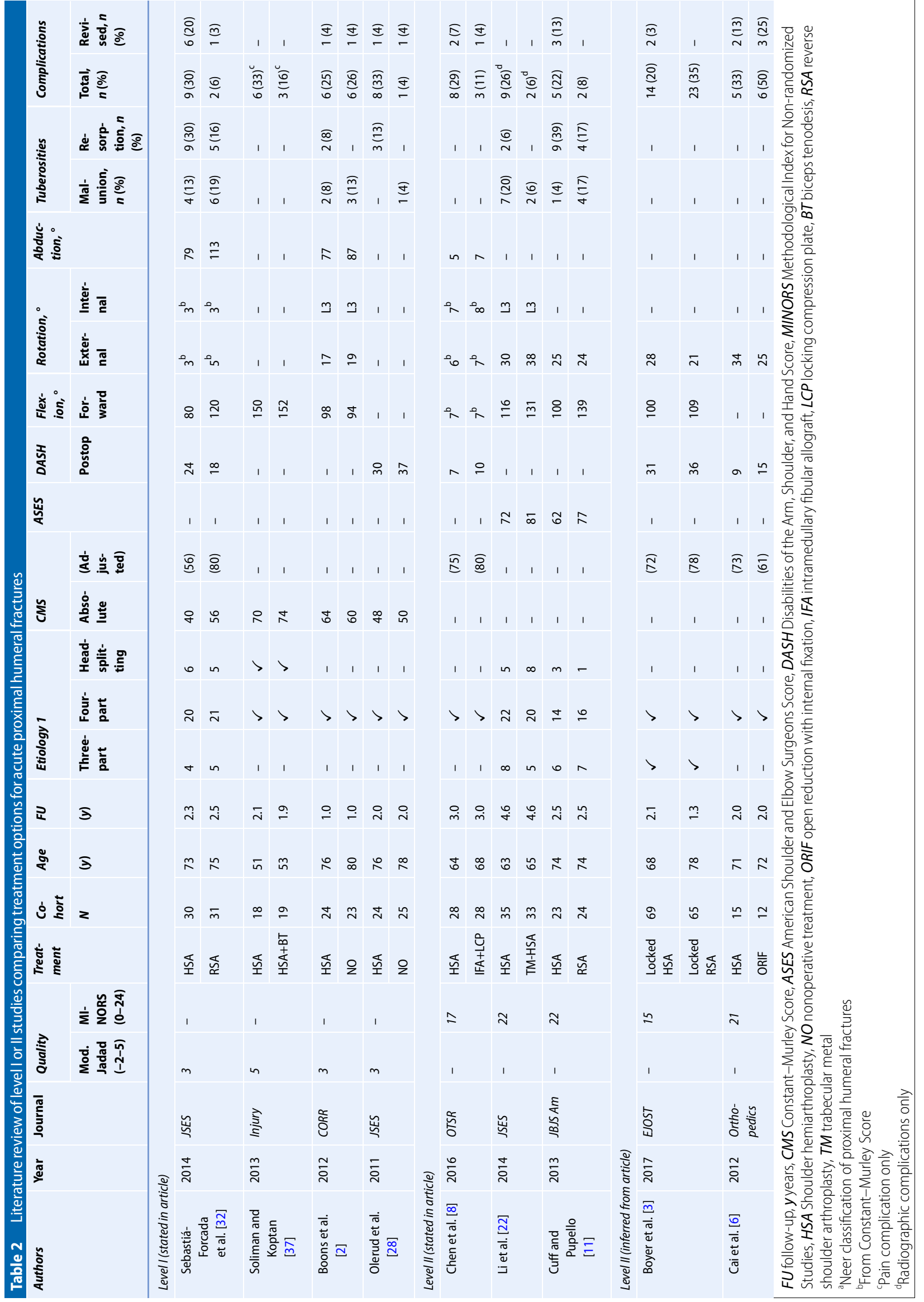




\section{Original Contribution}

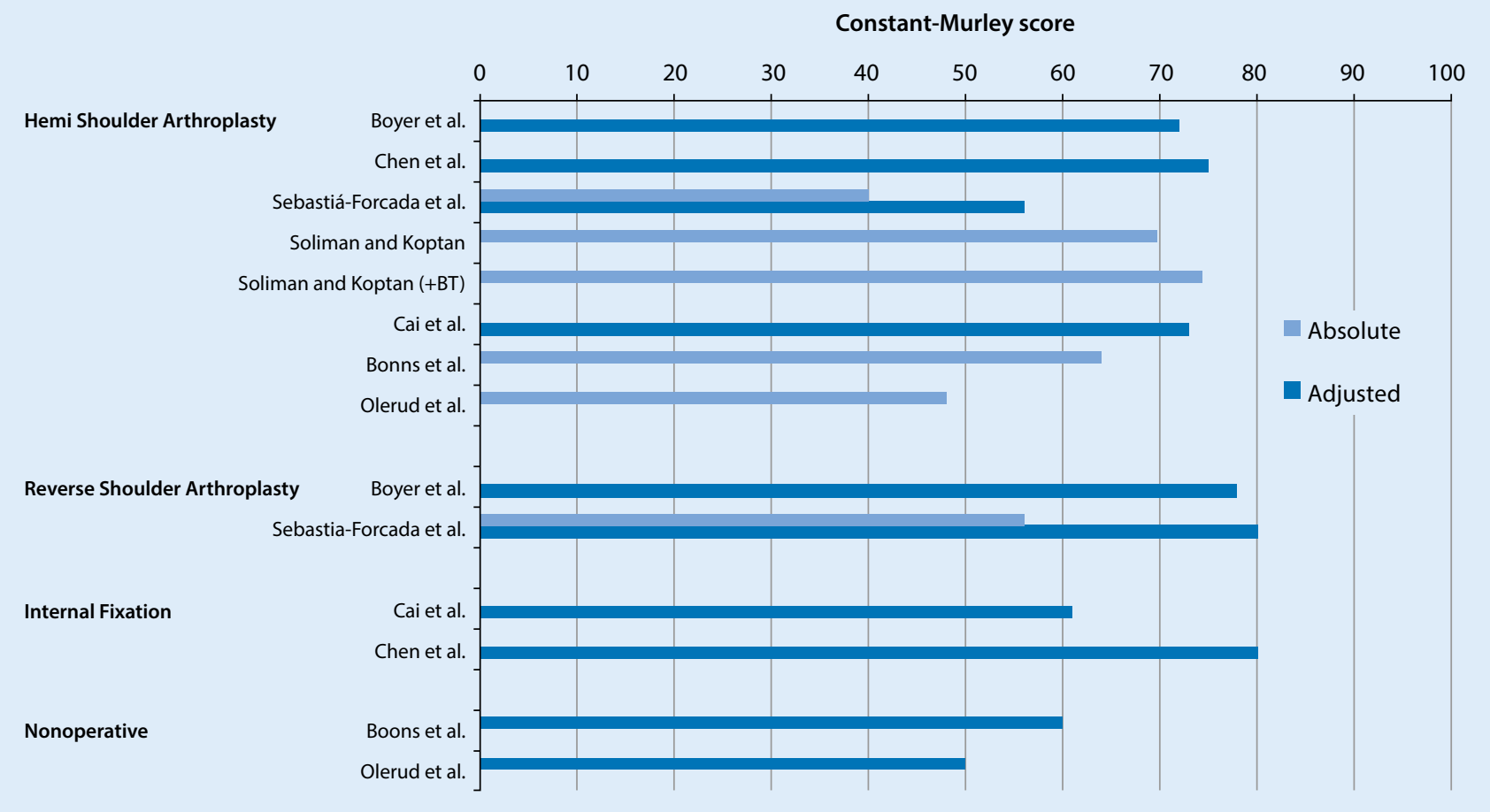

Fig. 4 A Reported postoperative absolute and/or adjusted Constant scores. BT biceps tenodesis

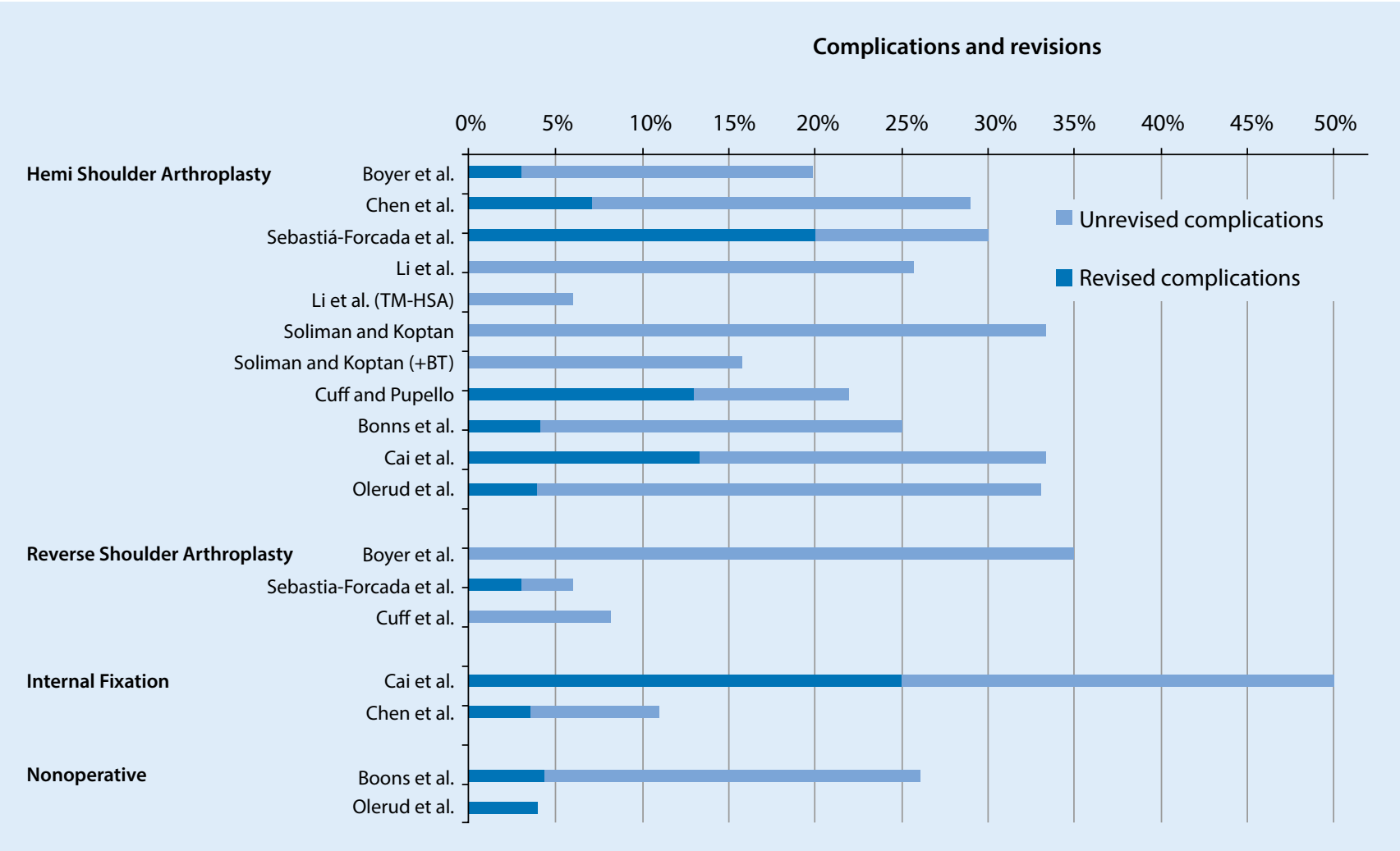

Fig. $5 \Delta$ Reported complication and revision rates.BT biceps tenodesis, TM-HSA trabecular metal shoulder hemiarthroplasty 
Table 3 Review of studies directly comparing shoulder hemiarthroplasty (HSA) vs. reverse shoulder arthroplasty (RSA)

Sebastia'-Forcada et al. [32]

JSES, level I (stated in article)

Cuff et al. [11]

JBJS Am, level II (stated in article)

HSA

30

Cohort, $n$

Males, $n$ (\%)

Age, years (SD)

5 (17)

Follow-up, years

$73.3(70-83)$

(SD)

Neer classification -

Three-part, $n \quad 4$ (13)

(\%)

Four-part, $n(\%) \quad 20(67)$

Head-splitting, $6(20)$

$n(\%)$

Constant-Murley Score (0-100)

Absolute

Adjusted

$40.0(8-74)$

ASES (0-100)

$55.8(11-100)$

UCLA (0-35)

DASH (0-55)

SST (0-15)

Forward flexion, ${ }^{\circ} \quad 80(20-180)$

(SD)

\section{Rotation}

External, ${ }^{\circ}(S D) \quad 3.3(0-10)$

Internal, ${ }^{\circ}(S D)$

$2.6(0-6)$

Tuberosities, $n$ (\%)

$$
\text { Healed }
$$

Malunion

$17(57)$

Resorption

4 (13)

$9(30)$

Complications, $n$ (\%)

Total $9(30)$

Revised

6 (20)

Kaplan-Meier survival (3.3 years)

Revision for $\%$
Revision or
clinical

failure, $\%$
RSA

31

4 (13)

HSA

23

$\begin{array}{ll}- & 23 \\ 0.731 & 9(39)\end{array}$

$74.7(70-85)$

$2.5(2.0-3.7)$

$-$

5 (16)

21 (68)

$5(16)$

$56.1(24-80)$

$79.7(35-100)$

$-$

$29.1 \quad(16-34)$

$17.5(12-30)$

$$
-
$$

$120(40-180)$

$4.7(0-10)$

$2.7(0-6)$

20 (65)

$6(19)$

5 (16)

$2(6)$

$1(3)$

197

0.211

9 (39)

$-$

$74.1(70-88)$

$3.3(3.0-4.0)$

RSA

24

$10(42)$

$74.8(70-86)$

$2.4(2.0-3.0)$

\begin{tabular}{|l|l|l|}
\hline 0,900 & - & - \\
\hline- & $6(26)$ & $7(29)$
\end{tabular}

$-\quad 14(61)$

- $3(13)$

$16(67)$

1 (4)

(29)

(13)

0.001

0.001

$-$

0.001

0.001

0.001

$-$

$-$

62 (28-84)

$-$

$100(30-170) \quad 139$

139

(102-172)

0.001

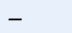

$-$

$\begin{array}{ll}0.023 & 25(0-48) \\ 0.914 & -\end{array}$

- $13(57)$

- $1(4)$

9 (39)

\section{$16(67)$}

$4(17)$

4 (17)

5 (22)

$3(13)$

2 (8)

$0(0)$

$24(8-42)$
$6(67)$
$4(17)$
$4(17)$
$2(8)$
$0(0)$

0.043

0.029
$113(50-170)$

$-\frac{10}{20}$

Boyer et al. [3]

EJOST, level II (inferred from article)

Locked HAS Locked RSA

$69 \quad 65$

- $\quad-$

$68.0(50-90) \quad 78.0(66-91)$

$2.1(0.9-10.0) \quad 1.3(0.5-3.4) \quad-$

(2.1 $(0.9-10.0)-1.3($

$\begin{array}{ll}- & - \\ - & \checkmark \\ - & \checkmark \\ - & -\end{array}$

$\checkmark$

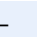

$2(11-120)$

$78(29-119)$ $<0.001$

$-$

$36(2-84)$

$0.006-$

$<0.001 \quad 100(25-160) \quad 109(30-160) \quad-$

- $90(35-160) \quad 100(10-150)$ -

HSA shoulder hemiarthroplasty, RSA reverse shoulder arthroplasty, ASES American Shoulder and Elbow Surgeons Score, UCLA University of California-Los Angeles Score, DASH Disabilities of the Arm, Shoulder, and Hand Score, SST Simple Shoulder Test, SD standard deviation

${ }^{a}$ Boyer et al. did not report on $p$ values

Our analysis confirms the current consensus on the superiority of RSA over HSA for the surgical treatment of acute PHF in elderly patients $[9,15,16,24$, $32,34,39]$. In their recent systematic review and meta-analysis including level I-IV studies, Gallinet et al. [16] , also concluded on the superiority of RSA, although they emphasized the lack of longterm studies. In a surgeon survey, Savin et al. [31] report that most practitioners agree that RSA is at least as reliable as, and often more adapted than, HSA for managing four-part PHF in el- derly patients. One clear advantage of RSA over HSA is that, by granting full function to the deltoid muscle, RSA reduces the effect of poor or slow tuberosity healing on outcomes [16]. Our analysis confirmed that tuberosity resorption is one of the most frequent causes for re- 
vision in HSA, but also suggested that in the presence of tuberosity resorption or malunion, the use of trabecular metal stems could significantly improve HSA outcomes [22]. Biceps tenodesis is another factor that may contribute to better HSA outcomes. Among the selected studies, one [37] compared outcomes of HSA alone with HSA with adjuvant biceps tenodesis. Adjuvant tenodesis improved functional outcomes and reduced pain; strikingly two cases of enduring pain after HSA alone were improved by postsurgical tenodesis.

The selected studies comparing HSA with surgical treatments other than RSA in elderly patients reported that intramedullary fibular allograft with locking compression plate versus HSA granted better clinical outcomes, greater range of motion, lower complication rates, and higher patient satisfaction [8], while ORIF and HSA did not differ significantly in functional outcomes. Therefore, ORIF could be considered an acceptable solution for less-demanding patients without humeral avascular necrosis and/or for less experienced surgeons [6]. Given the distinct risks (loss of reduction, screw cutout, intraarticular screw penetration, and avascular necrosis) and benefits (bone stock preservation, anatomic healing) of ORIF $[29,36,38]$, this technique is usually preferred for younger patients, which renders comparison difficult [13]. However, a recent study of 1791 surgically treated patients with PHF, from the American Surgeons National Surgical Quality Improvement Program database [12], reported that, compared with HSA and with RSA, ORIF is an independent protective factor against complications, although patient comorbidities remain stronger predictors of short-term complications than surgical treatment.

While there is general consensus on the surgical treatment of displaced fourpart fractures in younger patients, some controversy pertains to elderly patients, who are more likely to be osteoporotic, have low functional demands, and slow recovery. For them, less invasive procedures may provide adequate reduction and stable primary fixation [23]. The two level I studies that compared non- operative treatment with HSA in elderly patients $[2,28]$ observed no functional difference between patients treated conservatively or surgically at 1 or 2 years; however, conservative treatment was associated with more pain at 3 months [2] and lower quality of life [28].

\section{Limitations}

The present study has three main limitations: first, despite clear objectives and quantitative comparisons, the scarcity of level I and II studies limits the scope of our findings. Second, the absence of long-term level I and II studies does not permit firm conclusions. Third, we did not replicate our search in the Cochrane Library, nor did we consider gray literature. Nevertheless, to our knowledge, the present review is the first to summarize level I and II studies comparing outcomes of primary HSA or RSA for the treatment of acute PHF.

\section{Practical conclusion}

\section{- Reverse shoulder arthroplasty is a reliable treatment for acute PHF in elderly patients. \\ - It grants better outcomes and fewer complications than HSA at short-term follow-up. \\ - Future research is needed to establish the best surgical option for acute PHF in young patients.}

\section{Corresponding address

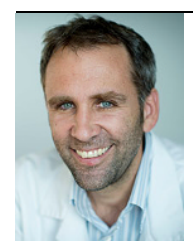 \\ PD Alexandre Lädermann, MD \\ Division of Orthopedics and Trauma Surgery, La Tour Hospital \\ Av. J.-D. Maillard 3, 1217 Meyrin, Switzerland alexandre.laedermann@ gmail.com}

\section{Compliance with ethical guidelines}

Conflict of interest A. Lädermann is a paid consultant from Wright, Arthrex and Medacta and received royalties from Wright. P. Collin is a paid consultant for Wright, Smith \& Nephew and ConMed and received royalties from Wright, Storz and Advanced Medica Applications. M. Scheibel is a paid consultant from Wright, Arthrex, Exactech, Storz and Medacta and received royalties from Wright. L. Nover, S. Piotton, and J. Chiu declare that they have no competing interests.

This article is a review article, it analyzes studies that already had ethical committee approval.

Open Access. This article is distributed under the terms of the Creative Commons Attribution 4.0 International License (http://creativecommons.org/licenses/by/ 4.0/), which permits unrestricted use, distribution, and reproduction in any medium, provided you give appropriate credit to the original author(s) and the source, provide a link to the Creative Commons license, and indicate if changes were made.

\section{References}

1. Anakwenze OA, Zoller S, Ahmad CS et al (2014) Reverse shoulder arthroplasty for acute proximal humerus fractures: a systematic review.J Shoulder Elbow Surg 23:e73-e80

2. Boons HW, Goosen JH, Van Grinsven S et al (2012) Hemiarthroplasty for humeral fourpart fractures for patients 65 years and older: a randomized controlled trial. Clin Orthop Relat Res 470:3483-3491

3. Boyer E, Menu G, Loisel F et al (2017) Cementless and locked prosthesis for the treatment of 3-part and 4-part proximal humerus fractures: prospective clinical evaluation of hemi- and reverse arthroplasty. Eur J Orthop Surg Traumatol 27:301-308

4. Boyle MJ, Youn SM, Frampton CM et al (2013) Functional outcomes of reverse shoulder arthroplasty compared with hemiarthroplasty for acute proximal humeral fractures. JShoulder Elbow Surg 22:32-37

5. Brorson S, Rasmussen JV, Olsen BS et al (2013) Reverse shoulder arthroplasty in acute fractures of the proximal humerus: a systematic review. Int J Shoulder Surg 7:70-78

6. Cai M, Tao K, Yang C et al (2012) Internal fixation versus shoulder hemiarthroplasty for displaced 4-part proximal humeral fractures in elderly patients. Orthopedics 35:e1340-e1346

7. Chalmers PN, Slikker W 3rd, Mall NA et al (2014) Reverse total shoulder arthroplasty for acute proximal humeral fracture: comparison to open reduction-internal fixation and hemiarthroplasty. JShoulder Elbow Surg 23:197-204

8. Chen H, Ji X, Gao Y et al (2016) Comparison of intramedullary fibular allograft with locking compression plate versus shoulder hemi-arthroplasty for repair of osteoporotic four-part proximal humerus fracture: Consecutive, prospective, controlled, and comparative study. Orthop Traumatol Surg Res 102:287-292

9. Chen L, Xing F, Xiang Z (2016) Effectiveness and safety of interventions for treating adults with displaced proximal humeral fracture: a network meta-analysis and systematic review. PLoS ONE 11:e166801

10. Cuff D, Clark R, Pupello D et al (2012) Reverse shoulder arthroplasty for the treatment of rotator cuff deficiency: a concise follow-up, at a minimum of five years, of a previous report. JBone Joint Surg Am 94:1996-2000

11. Cuff DJ, Pupello DR (2013) Comparison of hemiarthroplasty and reverse shoulder arthroplasty for the treatment of proximal humeral fractures 
in elderly patients. J Bone Joint Surg Am 95:2050-2055

12. Cvetanovich GL, Chalmers PN, Verma NN et al (2016) Open reduction internal fixation has fewer short-term complications than shoulder arthroplasty for proximal humeral fractures. J Shoulder Elbow Surg 25:624-631.e3

13. Dixit A, Cautela FS, Cooper CS et al (2018) ORIF versus arthroplasty for open proximal humerus fractures: Nationwide Inpatient Sample data between 1998 and 2013. JOrthop Traumatol 19:12

14. Ellman H, Hanker G, Bayer M (1986) Repair of the rotator cuff. End-result study of factors influencing reconstruction. J Bone Joint Surg Am 68:1136-1144

15. Ferrel JR, Trinh TQ, Fischer RA (2015) Reverse total shoulder arthroplasty versus hemiarthroplasty for proximal humeral fractures: a systematic review. JOrthop Trauma 29:60-68

16. Gallinet D, OhI X, Decroocq L et al (2018) Is reverse total shoulder arthroplasty more effective than hemiarthroplasty for treating displaced proximal humerus fractures in older adults? A systematic review and meta-analysis. Orthop Traumatol Surg Res 104:759-766

17. Germann G, Harth A, Wind G et al (2003) Standardisation and validation of the German version 2.0 of the Disability of Arm, Shoulder,Hand (DASH) questionnaire. Unfallchirurg 106:13-19

18. Giardella A, Ascione F, Mocchi M et al (2017) Reverse total shoulder versus angular stable plate treatment for proximal humeral fractures in over 65 years old patients. Muscles Ligaments Tendons J 7:271-278

19. Gummesson C, Atroshi I, Ekdahl C (2004) The quality of reporting and outcome measures in randomized clinical trials related to upperextremity disorders. J Hand Surg Am 29:727-734 (discussion 735-727)

20. Jadad AR, Moore RA, Carroll Detal (1996) Assessing the quality of reports of randomized clinical trials: is blinding necessary? Control Clin Trials 17:1-12

21. Katthagen JC, Grabowski S, Huber M et al (2016) Epidemiology and treatment reality of proximal humeral fractures at a level-1 trauma center. Obere Extremität 11:112-118

22. Li F, Zhu Y, Lu Y et al (2014) Hemiarthroplasty for the treatment of complex proximal humeral fractures: does a trabecular metal prosthesis make a difference? A prospective, comparative study with a minimum 3-year follow-up. J Shoulder Elb Surg 23:1437-1443

23. Maier D, Jaeger M, Izadpanah K et al (2014) Proximal humeral fracture treatment in adults. JBone Joint Surg Am 96:251-261

24. Mata-FinkA, Meinke M, Jones Cetal (2013) Reverse shoulder arthroplasty for treatment of proximal humeral fractures in older adults: a systematic review. JShoulder Elbow Surg 22:1737-1748

25. Michener LA, Mcclure PW, Sennett BJ (2002) American Shoulder and Elbow Surgeons Standardized Shoulder Assessment Form, patient self-report section: reliability, validity, and responsiveness. J ShoulderElbow Surg 11:587-594

26. Moher D, Liberati A, Tetzlaff J et al (2009) Preferred reporting items for systematic reviews and metaanalyses: the PRISMA statement. Plos Med 6:e1000097

27. Neer CS 2nd (1970) Displaced proximal humeral fractures. I. Classification and evaluation. J Bone Joint Surg Am 52:1077-1089

28. Olerud P, Ahrengart L, Ponzer S et al (2011) Hemiarthroplasty versus nonoperative treatment of displaced 4-part proximal humeral fractures in elderly patients: a randomized controlled trial. J Shoulder Elbow Surg 20:1025-1033

29. Owsley KC, Gorczyca JT (2008) Fracture displacement and screw cutout after open reduction and locked plate fixation of proximal humeral fractures [corrected. J Bone Joint Surg Am 90:233-240

30. Robinson CM, Page RS, Hill RM et al (2003) Primary hemiarthroplasty for treatment of proximal humeral fractures. J Bone Joint Surg Am 85a:1215-1223

31. Savin DD, Zamfirova I, lannotti J et al (2016) Survey study suggests that reverse total shoulder arthroplasty is becoming the treatment of choice for four-part fractures of the humeral head in the elderly. Int Orthop 40:1919-1925

32. Sebastia-Forcada E, Cebrian-Gomez R, LizaurUtrilla A et al (2014) Reverse shoulder arthroplasty versus hemiarthroplasty for acute proximal humeral fractures. A blinded, randomized, controlled, prospective study. J Shoulder Elb Surg 23:1419-1426

33. Seidl A, Sholder D, Warrender W et al (2017) Early versus late reverse shoulder arthroplasty for proximal humerus fractures: does it matter? Arch Bone Jt Surg 5:213-220

34. Shukla DR, Mcanany S, Kim J et al (2016) Hemiarthroplasty versus reverse shoulder arthroplasty for treatment of proximal humeral fractures: a meta-analysis. JShoulderElbow Surg 25:330-340

35. Slim K, Nini E, Forestier D et al (2003) Methodological index for non-randomized studies (minors): development and validation of a new instrument. ANZJ Surg 73:712-716

36. Solberg BD, Moon CN, Franco DP et al (2009) Surgical treatment of three and four-part proximal humeral fractures. J Bone Joint Surg Am 91:1689-1697

37. Soliman OA, Koptan WM (2013) Proximal humeral fractures treated with hemiarthroplasty: does tenodesis of the long head of the biceps improve results? Injury 44:461-464

38. Sudkamp N, Bayer J, Hepp P et al (2009) Open reduction and internal fixation of proximal humeral fractures with use of the locking proximal humerus plate. Results of a prospective, multicenter, observational study. J Bone Joint Surg Am 91:1320-1328

39. Wang J, Zhu Y, Zhang F et al (2016) Meta-analysis suggests that reverse shoulder arthroplasty in proximal humerus fractures is a better option than hemiarthroplasty in the elderly. Int Orthop 40:531-539 